\title{
On the definition of urban heat island intensity: the "rural" reference
}

\author{
Javier Martin-Vide $^{1 *}$, Pablo Sarricolea ${ }^{1,2}$ and M. Carmen Moreno-García ${ }^{1}$ \\ ${ }^{1}$ Group of Climatology, University of Barcelona, Barcelona, Spain, ${ }^{2}$ Department of Geography, University of Chile, Santiago, \\ Chile
}

Keywords: urban heat island, temperature measurement, non-urban point, altitude, distance to the sea

\section{Introduction}

One of the fundamental objectives of many studies on urban heat islands (UHI) involves establishing their intensity on determined nights or, if there is a sufficiently high number of observations, their maximum intensity and average intensity can also be ascertained. Regardless of the methodology employed, whether it refers to (1) differences between two fixed observatories, one urban and another peripheral or non-urban, (2) mobile urban transects or (3) remote sensing, in the end it is a question of providing a value of thermal differences between contrasted points or sectors, one urban and another that could be termed non-urban. Thus, the intensity of the UHI is seen in the temperature difference expressed at a given time between the hottest sector of the city and the non-urban space surrounding this. The intensity of the heat island is the simplest and most quantitative indicator of the thermal modification imposed by the city upon the territory in which it is situated and of its relative warming in relation to the surrounding rural environment at night time (Kim and Baik, 2002; Memon et al., 2009).

Edited by:

Tomas Halenka,

Charles University, Czech Republic

Reviewed by:

Prodromos Zanis,

Aristotle University of Thessaloniki,

Greece

Krys Blazejczyk,

Polish Academy of Sciences, Poland

*Correspondence:

Javier Martin-Vide,

jmartinvide@ub.edu

\section{Background}

However, the concept of the UHI, requires a definition that establish comparisons among cities and makes precise appraisals of the magnitude of this phenomenon in a given city on different dates. The first basic step entails the choice of two points, one urban and the other non-urban. In relation to the urban point, there is generally less uncertainty, because it is established in the hottest part of the city on average, usually in the center. Even without ad hoc observations, in many cities it is quite easy to determine the hottest area at night. If this were not the case, a pilot measurement campaign could establish the hottest point. It should be kept in mind that the hottest part of the city is not always the same, as can be seen by means of remote sensing in Santiago de Chile (Sarricolea and Martin-Vide, 2014), although the present paper will refer to these urban and non-urban points. The latter must be selected with great care. Ideally, the non-urban point should be close to the city, but in a rural area, or, better still, with natural vegetation cover. The adjective "rural" has traditionally been associated with the location of the non-urban or reference point and thus, UHI intensity has commonly been defined as the temperature difference between urban and rural places (or areas), $\Delta \mathrm{T}_{\mathrm{u}-\mathrm{r}}=\mathrm{T}_{\mathrm{u}}-\mathrm{T}_{\mathrm{r}}$, where $\Delta \mathrm{T}_{\mathrm{u}-\mathrm{r}}$ is UHI intensity, $\mathrm{T}_{\mathrm{u}}$ is urban temperature and $\mathrm{T}_{\mathrm{r}}$ rural temperature. Of course, the non-urban point must be situated outside the constructed urban space or any surface that has been modified by asphalt, cement, etc..., in order for anthropogenic heat to be negligible in its energy balance, for the sensible and latent heat to be as similar as possible to that of natural cover, and for the radiation balance to present albedos and emissivity coefficients that are also similar to those of a natural environment. However, the boundaries of the city are often inaccurate, because the urban continuum sometimes lacks clear limits, presenting a transition toward typically rural land uses. Most cities do not border on the rural space, but rather on periurban zones, rururban ones, etc..., which are influenced to some extent 
by the city. Even rigorous studies make use of somewhat vague expressions such "nearby rural area" for the non-urban point or sector (Van Hove et al., 2011). To find this non-urban point we would, in certain cases, have to cover such a distance that we would enter a climatic domain, or a given weather type at a determined moment, different from the city being studied. On comparing their temperatures, the differences would not only result from the urban effect, but also from the existence of different climates or weather. Many studies have failed to select the suitable non-urban point, selecting an available observatory outside the city, even if this does not provide the ideal conditions. Furthermore, much effort has been invested in zoning the land uses surrounding cities in order to subject them to climatic and meteorological study and to establish UHI intensities. Indeed, some urban climatologists have proposed detailed classifications of space and of urban and rural landscapes, particularly of their transition zones. In this sense, we can cite the work of Oke (2006), who proposes seven Urban Climate Zones (UCZ), from $\mathrm{N}^{\circ} 1$, intensely developed urban zones with detached close-set highrise buildings with cladding, e.g., downtown towers, presenting over $90 \%$ built (impermeable) surface, to $\mathrm{N}^{\circ} 7$, scattered semirural development houses in a natural or agricultural area, e.g., farms, estates, with less than $10 \%$ built surface. This classification is used, for instance, to accurately compare the maximum urban heat island intensities of 19 Dutch cities (Van Hove et al., 2011). Other authors also assume that the rural, or reference, point must possess less than $10 \%$ of constructed surface (Wing-Yee, 2010). Using remote sensing, the urban land cover explains the UHI intensities of many European cities (Zhou et al., 2013). Stewart and Oke (2009) expanded the UCZ classification into a more comprehensive system called Local Climate Zones (LCZ). It attempts to categorize the landscape "universe" into $19 \mathrm{LCZ}$ belonging to four landscape series (city, agricultural, natural, and mixed) according to surface cover, surface structure, and cultural activity. This procedure has been employed, for example, by Siu and Hart (2013) for Hong Kong. In this sense, the case of Hong Kong is highly illustrative of the problems involved in choosing the points, particularly the rural, or non-urban, one. These authors conclude that the rural stations used in previous studies are not representative, and thus, the UHI intensities previously calculated for Hong Kong may have been underestimated.

Moreover, there is an effect on the leeward side of the city, which at a given moment depends mainly upon wind direction. If on a determined night the non-urban point is subjected to this effect, the difference between this point and the city center will be attenuated. Therefore, depending on wind direction, the urban influence upon the leeward side of the city may or may not affect the non-urban point.

Simplifying Lowry's additive scheme (Lowry, 1977), temperature measured at the urban point is a function of the climate of the region it is located in, plus the effect of local geographic factors and urbanization, whereas the temperature at the non-urban point of the regional climate itself and the effect of local geographic factors. If the local geographic factors are similar at both points, then the difference between both temperatures will express the effect of the city, which constitutes our objective. If we are to provide a correct and comparable value of UHI intensity, it is vital to choose a non-urban point with an altitude and distance from the sea, or from the existing bodies of water, comparable to those of the urban point. These two geographic factors, altitude and distance from the sea, are decisive, whilst others, such as latitude, do not cause appreciable differences between the two points. If the non-urban point is situated, for instance, higher than the urban one, then its average temperature will be appreciably lower or, on occasions, higher if thermal inversion occurs. In any case, the urban effect would be camouflaged on calculating the temperature difference. There is therefore a need to establish the margin of altitude differences between the urban and non-urban points in order to consider that their temperature differences reveal only the urban effect. If the average vertical temperature gradient is considered $\left(0.65^{\circ} \mathrm{C} / 100 \mathrm{~m}\right), 30.8 \mathrm{~m}$ will cause a variation of $0.2^{\circ} \mathrm{C}$, which is of the order of accuracy of many temperature measurements. Thus, as a general rule, the altitude of the non-urban point should not differ from the urban one by more than \pm approximately $30 \mathrm{~m}$. In the very well-documented doctoral thesis by Siu (2011) the points finally selected present an altitude difference of $27 \mathrm{~m}$. In the case of Barcelona, the altitude difference between the points of contrast is approximately $20 \mathrm{~m}$ (Moreno-Garcia, 1994). On nights with intense ground thermal inversion, very often associated with synoptic situations (anticyclonic) which give rise to intense heat islands, $30 \mathrm{~m}$ constitutes an altitudinal contrast that can cause substantial temperature differences, of several degrees centigrade. In these cases, a non-urban point situated at a lower (higher) altitude would overestimate (underestimate) the urban effect. For these nights, altitudinal differences of only $10 \mathrm{~m}$ would represent a non-urban bias in the calculated intensities of the heat island. In short, the altitudinal difference between the urban and non-urban points should never surpass $30 \mathrm{~m}$, and, if possible, should be less than $10 \mathrm{~m}$. In the event that the latter criterion were not possible, the intensity of the heat island established on nights with intense thermal inversion has to be subjected to correction. This is also the case if it were impossible to find a non-urban point with an altitude difference of $30 \mathrm{~m}$ or less with respect to the urban point (for instance, in a city totally occupying the bottom of a closed-in valley).

It is a well-known fact that bodies of water regulate temperature and attenuate daily and seasonal temperature differences, as can be seen in the limited daily and annual temperature ranges on coasts and islands. For this reason, it is not recommendable to choose a non-urban point more distant from, or close to, the coastline than the urban point, but this requires further discussion. Once again, there is a need to specify the maximum assumable value for this difference in distance from the coast. Very few studies have addressed this issue, which does not provide one single result, given that the influence of distance from the sea is very strong in a coastal area and negligible in an inland environment far from the coast or separated from it by reliefs. In the latter case, in a large inland urban area, with a continental climate, even a difference of tens of kilometers in distance from the sea between the urban and non-urban points will not cause any temperature differences. On the contrary, next to the coast or the edge of a big lake, the effect of the 
body of water rapidly decreases as one moves away from it. It is highly likely that the relationship between the influence of distance from the sea and temperature is not a linear one. In an environment open to the sea such as the plains of Valencia (Eastern Spain), annual average minimum temperature decreases by approximately $0.16^{\circ} \mathrm{C} / \mathrm{km}$ with distance from the sea; in January this variation is $0.23^{\circ} \mathrm{C} / \mathrm{km}$ and in July $0.11^{\circ} \mathrm{C} / \mathrm{km}$, approximately (Ninyerola et al., 2005). If the city is coastal, the distance from the sea of the urban and non-urban points should not differ by much more than over $800 \mathrm{~m}$ (in the case cited, and as an annual average, in view of the lack of specific records, a difference of $0.2^{\circ} \mathrm{C} / \mathrm{km}$ would occur in January with a difference between distances of $870 \mathrm{~m}$ ). As can be seen in the example given, the factor "distance from the sea" depends upon time of year and also latitude, due to the influence of water and air temperatures and of the marine currents, which possess their own thermal anomaly.

\section{References}

Kim, Y.-H., and Baik, J.-J. (2002). Maximum urban heat island intensity in Seoul. J. Appl. Meteorol. 41, 651-659. doi: 10.1175/15200450(2002)041<0651:MUHIII> 2.0.CO;2

Lowry, W. P. (1977). Empirical estimation of urban effects on climate: a problem analysis. J. Appl. Meteorol. 16, 129-135.

Memon, R. A., Leung, D. Y. C., and Liu, C.-H. (2009). An investigation of urban heat island intensity (UHII) as an indicator of urban heating. Atmos. Res. 94, 491-500. doi: 10.1016/j.atmosres.2009.07.006

Moreno-Garcia, M. C. (1994). Intensity and form of the urban heat island in Barcelona. Int. J. Climatol. 14, 705-710. doi: 10.1002/joc.33701 40609

Ninyerola, M., Pons, X., and Roure, J. M. (2005). Atlas Climático Digital de la Península Ibérica. Metodología y Aplicaciones en Bioclimatología y Geobotánica. Universidad Autónoma de Barcelona, Bellaterra. Available online at: http:// www.opengis.uab.es/wms/iberia/index.htm

Oke, T. R. (2006). Initial Guidance to Obtain Representative Meteorological Observations at Urban Sites. IOM Report No.81, WMO/TD. No. 1250, World Meteorological Organization, Geneva.

Sarricolea, P., and Martin-Vide, J. (2014). El estudio de la isla de calor urbana de superficie del área metropolitana de santiago de chile con imágenes terra-MODIS y análisis de componentes principales. Rev. Geogr. Norte Grande 57, 123-141. doi: 10.4067/S0718-340220140001 00009

Siu, L. W. (2011). Quantifying the Urban Heat Island (UHI) Intensity in Hong Kong. Master of Philosophy, The University of Hong Kong.

\section{Conclusions}

In summary, the intensity of the heat island is the simplest and quantitative indicator of the thermal modification imposed by the city upon the territory. Therefore, the most important aspects to be considered in this definition are, in the first place, that two points (urban and non-urban) that follow the scheme of Stewart and Oke (2009), that is, a point in the urban center and another with less than $10 \%$ floor area, also, the altitudinal difference between the urban and non-urban points should never surpass $30 \mathrm{~m}$, and, if possible, should be less than $10 \mathrm{~m}$. Finally, the proximity to water bodies in urban and non-urban points should be similar and ideally over 800 meters.

\section{Acknowledgments}

Institut de l'Aigua (University of Barcelona, Spain), Grup de Climatologia 2014SGR300 (Catalan Government).

Siu, L. W., and Hart, M. A. (2013). Quantifying urban heat island intensity in Hong Kong SAR, China. Environ. Monit. Assess. 185, 4383-4398. doi: 10.1007/s10661-012-2876-6

Stewart, I., and Oke, T. (2009). "Classifying urban climate field sites by local climate zones: the case of Nagano, Japan," in The Seventh International Conference on Urban Climate (Yokohama).

Van Hove, L. W. A., Steeneveld, G. J., Jacobs, C. M. J., Heusinkveld, B. G., Elbers, J. A., Moors, E. J., et al. (2011). Exploring the Urban Heat Island Intensity of Dutch Cities. Assessment Based on a Literature Review, Recent Meteorological Observations and Datasets Provided by Hobby Meteorologists. Alterra, report 2170, Alterra, Wageningen.

Wing-Yee, F. (2010). Characterizing Urban Heat Island and its Effects in Hong Kong. Doctoral thesis, The Hong Kong Polytechnic University.

Zhou, B., Rybski, D., and Kropp, J. P. (2013). On the statistics of urban heat island intensity. Geophys. Res. Lett. 40, 5486-5491. doi: 10.1002/2013GL057320

Conflict of Interest Statement: The authors declare that the research was conducted in the absence of any commercial or financial relationships that could be construed as a potential conflict of interest.

Copyright (c) 2015 Martin-Vide, Sarricolea and Moreno-García. This is an openaccess article distributed under the terms of the Creative Commons Attribution License (CC BY). The use, distribution or reproduction in other forums is permitted, provided the original author(s) or licensor are credited and that the original publication in this journal is cited, in accordance with accepted academic practice. No use, distribution or reproduction is permitted which does not comply with these terms. 